\title{
How IS Contribute to the Development of a Sustainable Procurement Policy
}

\author{
Oihab Allal-Chérif \\ Professor at BEM Bordeaux Management School France \\ 680 Cours de le Liberation 33400 Talence France \\ oihab@bem.edu
}

\begin{abstract}
Sustainability has become a central corporate concern as well as a key factor of success in terms of both image and productivity. In turn, the procurement function is crucial to the definition and implementation of a sustainability policy. It drives a company's sourcing activities and connects its other functions (i.e. internal customers) to external suppliers and providers. IS, which have come under heavy criticism due to their negative environmental effects, can provide support services while also stimulating and disseminating sustainable purchase policies. The present study combines a literature review with a qualitative study to illustrate this emergence and show how IS can and will contribute to the development of corporate sustainable procurement policies. Using an exploratory approach and constructivist positioning, a "business forecasting" method is implemented to suggest a possible future for sustainable procurement management, along with a new role for IS. Towards this end, a scenario is coconstructed by 12 procurement function experts responding to questions about their customs and practices and talking about their experiences, the effects of the rising wave of environmentalism, the problems they face in implementing and optimizing IS and their professional. They also offer a few predictions and suggest new methods and modes of coordination. Procurement functions and IS departments work together to reduce the environmental footprint of technology and to exert greater influence on collaboration and teamwork by building an economic environment that is more viable and livable and also fairer.
\end{abstract}

Keywords: Procurement, IS, sustainability, collaboration, forecasting.

\section{Introduction}

The rapid generalization of management IS (IS) can be partially explained by such systems' ability to improve organizational performance, particularly as regards productivity. Inter alia, IS enable a leaner management of flows by reducing delays and errors, increasing reliability and responsiveness, eliminating undesirable tasks, optimizing resources and facilitating decision-making. Information and communications technology (ICT) is a pillar of corporate activity because it (1) embodies competitive advantage in and of itself thanks to its optimization of processes, introduction of a high-performance technological watch function and improvement in knowledge management, while also (2) contributing as a tool that creates indirect competitive advantage through, for instance, the development of new 
killer technologies. Professionals try to achieve savings at both the design and utilization levels. IS' sustainable performance is more than ever a challenge and an opportunity for IS departments. Yet sustainable performance must also overcome a number of hurdles, like how to ensure that IS that are increasingly complex, open and interdependent can function sustainably and provide top performance, or how to take advantage of innovations and new kinds of usage to create sustainable performance and value. The idea here is that the procurement function plays has a particularly significant role to play since it transforms intra-organizational IS into integrated management programs while using the Internet and inter-organizational tools as platforms for managing supply chains and supplier relationships. The present study therefore focuses on procurement functions' management and use of IS for sustainability purposes. The first section construes procurement management as a paragon of sustainability since it is this function that wields the action lever that is paramount in environmental, social and societal performance terms. A literature review then highlights procurement IS' role in improving performance. The second section describes a research protocol based on exploratory and constructivist approaches associating "business forecasting" and scenario methods. 12 business experts are interviewed according to a precise interview format and asked to differentiate between good and bad practice. The third section presents a number of predictions grounded in literature and discussions with experts.

\section{IS Serving the Sustainable Procurement Function}

Procurement management and IS management both play highly strategic roles in modern companies, particularly large multinationals. Thus, associating these two functions creates a powerful internal coalition capable of developing tools that will advance the cause of sustainability in its economic, ecological and social dimensions.

\subsection{Procurement Mutates from Cost-Killing to Sustainable Value Creation}

Little by little, large, vertical and very hierarchical firms have been replaced by horizontal organizations that concentrate on what they view as their core business. In turn, this has meant growing reliance on market-based actions [1]. The procurement function has developed naturally, with each outsourced activity giving birth to one or several new procurement portfolios. Relying on external providers for increasingly strategic tasks has created a need for highly qualified and specialized purchasers. The fact that the procurement functions are starting to account for a rising percentage of total corporate revenues has underpinned their growth and given them considerable power since each procurement decision can have major financial consequences [7]. The current crisis has further amplified this phenomenon. At the same time, it appears that after a period during which Procurement frantically sought to cut costs and rationalize processes, it now concentrates on things like technological watch, innovation, sustainability and global B2B marketing.

The emergence of networked companies has led to a redefinition of firms' relationship to their territories [16]. Right-sourcing and in-sourcing have started to replace outsourcing. As a solution, cooperative management of the procurement function is a budding success that very few companies had thought about before the crisis but which 
suddenly became much more popular afterwards. A cooperative management of the procurement function can only be found in a few very mature pioneering companies such as Schneider Electric, IBM or Nestlé. This method has gained many fans since the outbreak of the economic crisis and is being applied to both internal and external collaborations. Internally, it can materialize in the form of (1) synergies between Procurement and other functions such as Research and Development or Marketing, (2) decisions taken jointly by different hierarchical levels, and (3) cross-departmental project management run by procurement professionals. Externally, the main forms of a cooperative management of procurement are (1) the technological co-development or co-design of products in conjunction with suppliers, (2) innovation sponsoring, (3) the assisted piloting of production (4) the integration of IS, (5) the automation or externalization of some purchases, and (6) collaborative strategic management [2].

\subsection{Inter-Organizational IS (IOIS) Serving the Procurement Function}

Networks enable members to concentrate on their core business and externalize the rest of their activities. They organize interdependency relationships between multitudes of firms coordinate physical, financial and information flows and establish standards [4]. An e-procurement IS constitutes a platform that is specific to a network of purchasers and suppliers, enabling them to communicate and collaborate. It is a "virtual" and "decentralized" website where companies can meet and interact with one another and with partners such as IT service providers, consultants, banks, insurance companies or marketing firms. Unlike traditional markets, electronic markets make massive usage of ICT. They are more transparent, making it easier to create relationships among a large number of actors found anywhere in the world and helping people to obtain information more easily about companies, products, technologies or legislation.

Procurement IS are a response to researchers" "premonitions" or efforts to anticipate both changes in the relationships between actors operating in one and the same market as well as their strategic moves. Four criteria can be used to distinguish corporate networks: whether they have a high or low degree of specificity; and whether their logic is additive or complementary. In particular, additive logic consists of creating new competencies and resources by exploiting the competencies or resources of other companies cooperating within the same network. It is this pooling of complementary activities that helps to bolster the value chain of companies in a transactional network.

\subsection{Procurement IS: Disputed Tools in the Service of Sustainability}

ICT plays an increasingly important role in relationship between business and the ecosystem, or the human, social, geographic, urban and rural environment. IS departments can innovate and offer proposals that are decisive for the conservation of natural spaces while limiting consumption of energy or other resources and helping in the battle against global warming. More specifically, just measuring the "sustainability" of an economic activity requires very reliable and high performance IT tools. IS make it possible, for example, to find ways of measuring a product's pollutant substances or contribution to global warming in $\mathrm{CO} 2$ equivalency terms. This carbon footprint can be analyzed and lowered by means of an IS that will compare the company's environmental performances to current standards. 
Above and beyond the purely financial dimension of cost-cutting facilitated by procurement IS, such IS also feature a very strong social dimension insofar as they help many employees to link up via a single platform where they can exchange information, conduct negotiations, share resources and collaborate on projects. This means that economic relations cannot be dissociated from social relations, some of whose components - particularly trust - influence commercial mechanisms and embody the principle that economic activities are first and foremost comprised of social activities and networks [9]. For companies to be able to work together, it is indispensable that the individuals representing them agree about the conditions of their collaboration and learn to know and trust one another.

\section{3 “Business Forecasting” Associated with the Scenarios Method}

To apprehend the future of procurement functions and discover how they might use IS to go green; it is worth scrutinizing the expectations and forecasts of the actors working in this function. The purpose here is to adopt a "global, rational and appropriation-oriented approach" that is action-oriented. After all, procurement function management should be part of a long-term vision based on a precise and subtle perception of weak signals announcing future developments, detected by persons immerged in the procurement sphere but who want to have some influence on and control over their business.

\subsection{Exploratory Constructivist and Qualitative Methodology}

Procurement IS are relatively new tools that have generated a more or less limited number of studies. Hence the idea of exploring such virtual technologies and their universe to try and deduce theories and predictions can be useful for the future. A polemic tone is adopted in the style of an appeal to researchers that they find a different way of conducting scientific research [6]. This can be contrasted with the hypothetical-deductive method where researchers explain phenomena based on postulates. In the present study, the starting point is the sum total of practices used by actors-experts offering their vision of a preferable future path for procurement IS. Grounded theory derives from an immersion in the empirical data that is associated with the theories covering the phenomena being observed. These are "new theories" that supplement existing theory and explain new situations.

Epistemological positioning has had a major influence on the way in which this study was run and on its findings. It is therefore important to clarify this positioning to justify the method chosen, validate the knowledge produced and legitimize the results obtained. A choice had to be made between the three epistemological stances proposed in literature: positivism; interpretivism; and constructivism [17]. More specifically, constructivism focuses on social interactions and processes as modes for explaining a reality [5] that is produced by the logical individual actors who are participating in it and which therefore undergoes permanent reconstruction. It is the rationality of action manifested by each of the actors involved in particular decisions in this case, procurement processes - that will determine the reality of the situations in which they find themselves [8]. Individuals make constructions and are constructed 
by engaging in interactional phenomena together with other individuals, in a particular environment and using certain tools that force them to make choices.

\subsection{Procurement Forecasts: Towards Structural and Functional Anticipation}

The purpose of this article is to co-construct, according to rigorous principles, a shared representation of procurement IS' utilization within a procurement function management framework, thanks to viewpoints expressed by the dozen actor-experts whom we interviewed. Environmental changes can to some extent be predicted and even partially controlled. The desire to adopt a proactive attitude towards sustainability, i.e. to avoid being overwhelmed by rising environmentalism, is also an argument in favor of using business forecasting within this kind of framework. Prepared adaptation will always be much more effective than simply reacting to the unexpected.

The scenarios method is a good way of stimulating the imagination and reflection of selected experts since they are supposed to envision how the procurement function - construed as a complex set of professions, relationships and tools - might evolve towards a possible future. The role that IS play in the changing management of the procurement function, plus their role as levers of sustainable action will emerge naturally through these scenarios. The procurement professionals we interviewed accepted to co-construct a new profession for purchasers, based on virtual purchasers born out of the changes in their old profession and its convergence with others, characterized by new qualifications and kinds of expertise; new tools; and a markedly different behavior towards their organizations and the environment.

\subsection{Selection of Business Experts and Interview Protocol}

For this study, 12 purchasers and procurement managers were chosen from companies of varying sizes and different sectors. This diversity allowed for a sufficient heterogeneity of viewpoints to cover the lion's share of competencies, activities and responsibilities associated with the kinds of purchasers who were the object of analysis.

Table 1. Presentation of panel of procurement manager interviewees

\begin{tabular}{|ccccc|}
\hline Code & Function & Staff & Revenues & Sector \\
\hline A1 & Procurement Manager & 400,000 & $€ 104$ billion & IT \\
\hline A2 & Procurement Manager & 270,000 & $€ 75$ billion & Food \\
\hline A3 & IS/Procurement Manager & 200,000 & $€ 19$ billion & Electricity \\
\hline A4 & Procurement Director & 120,000 & $€ 180$ billion & Energy \\
\hline A5 & Procurement Manager & 100,000 & $€ 40$ billion & Machines \\
\hline A6 & Purchaser & 70,000 & $€ 20$ billion & Cosmetics \\
\hline A7 & Procurement Manager & 55,000 & $€ 10$ billion & Distribution \\
\hline A8 & Procurement Director & 9,000 & $€ 5,1$ billion & Telecoms \\
\hline A9 & Procurement Director & 8,000 & $€ 2,5$ billion & Textiles \\
\hline A10 & Procurement Director & 1,400 & $€ 800$ millions & Healthcare \\
\hline A11 & Managing Director & 47 & $€ 200$ millions & Equipment \\
\hline A12 & Managing Director & 20 & $€ 50$ millions & IT \\
\hline
\end{tabular}


To minimize subjectivity and interpretation effects, only half of these experts were previously known to the interviewers. The project's exploratory status and focus on the future was coherent with this approach since the business experts being interviewed would talk about their experiences, answer one another and communicate specific experiences relating to the themes in question. Thus, it is a whole research universe that was reconstructed, with the singularity of each background and viewpoint considered crucial in evaluating lines of questioning and potential hypotheses [15].

\section{New Tools for a New Sustainable Procurement Policy}

Since the 1990s, purchasers have often been assimilated with cost-killers. However, given the extreme pressure on prices and suppliers, what came out of this has been un-fair trade characterized by destabilization maneuvers and bargaining practices, along with highly compartmentalized management focused on independent profit centers and short-term profitability objectives.

\subsection{The Rise of Sustainable e-Procurement: Managing Relations with Suppliers}

As explained by A5, "In our business, the integration of suppliers has become fundamental. We must be humble and accept that our suppliers have business expertise that we lack. Our roadmap reprises our suppliers' roadmaps. Our future depends on them and our success depends on their success". In some sectors like automobiles, IT or aeronautics, the integration of suppliers is a key strategic axis for companies. The advent of concepts such as integrated SRM supplier relationship management and CRM customer relationship management illustrate this evolution. According to A2, "We understood that we could not make profits on our suppliers' backs but that we had to consider them as extensions of ourselves and treat them more fairly by valuing their talents". This has led to the advent of new and more cooperative or integrated forms of subcontracting featuring joint objectives and the pooling of knowledge, competencies and resources in a bid to achieve success through collective endeavor.

Thus, organizational proximity can be supplemented by electronic proximity in a way that cumulates or replaces inter-firm geographic proximity and helps companies to access their collective strengths and overcome individual weaknesses. As A8 says, purchasers "need to travel less but is completely utopian to imagine that they won't have to travel at all simply because they use IT. Clearly, this would be fantastic from a green perspective but the best thing in business is always a good handshake. We need to see our contacts otherwise than through the deformed prism of a webcam". Sustainable, responsible and ethical procurement will also become a standard applied to all sourcing activities, i.e. it will no longer be viewed as a more or less marginal aspect of procurement. Rather than economic calculation, it is the stability of partnerships, the stimulation of innovation and the development of new projects that become the priority. Unilateral decisions are no longer taken in the exclusive interest of one stage in the supply chain - what happens instead are joint decisions that help to consolidate the overall structure. 


\subsection{IS as Tools for Measuring, Analyzing and Aiding Sustainable Decisions}

As a purchaser specialized in energy in a company that sells energy, A4 explains: "Energy is a question of who has the strongest nerves! We see sustainability as a key issue for both customers and suppliers, even as we try to act as trailblazers in this area to avoid being victimized by a green dictatorship. We have carried out an in-depth modification of our practices, products and internal and external relationships while also perfecting our measurement tools to achieve a broader and more precise vision of our environment". All of the purchasers interviewed in the present study were aware of very sudden changes that will occur over the next few years and sought to be the actors of this evolution rather than the victims.

Ecological performance contrasts with economic performance for most of the experts-actors we interviewed. A2 said, "We have signed the UN Global Compact and got all our suppliers to sign it but the day when I presented plans for auditing and supporting all of these suppliers in a sustainability drive, I was told that it costs too much so we didn't do anything concrete". Geographic IS (GIS) are a crucial issue in purchasers' decision-making and in the advent of a future-oriented vision of the markets. Such IS are currently evolving from production-related IT to collaborative information sharing IT used to manage communitarian projects and redevelop the territories where companies operate. More complete, transparent and higher quality information helps to rapidly raise awareness of problems associated with sustainability and enables an informed decision that should increase the effectiveness of the policies being implemented. For some purchasers, GIS are indispensable. A1 uses them every day to compare sites and markets worldwide, explaining that, "Without geographic tools, I couldn't do my work - almost nothing! All of my decisions are based on data that has been collected and analyzed by digital intelligence of this kind. Geographic IS help me to assess opportunities and risks and engage in impact studies, in particular in the sustainability arena". GIS also play an increasingly crucial role in choices about transportation, the localization of new structures and sourcing from new emerging country suppliers.

\subsection{Re-establishing Customers and Partners' Trust in Procurement IS}

The advent of sustainability in companies, materializing in ethical, fair and ecological trade, has changed the world and led to an in-depth modification of purchasers' behavior. The procurement function would appear to be a particularly apt area for applying the rules of sustainability, given its openness and actions on the external environment, and because of its interactions with other corporate functions. IS are used to optimize costs more than resources, and also to organize radical competition between suppliers instead of integrating them. As such, IS provoke mistrust and are associated with purchasers' destructive practices. According to A11, "When we suggest to our suppliers that they collaborate on new IT tools, how do you think that they are going to react? They'll be afraid! They don't want to be controlled by us and be subject to even more pressure than they already are". Companies are not credible when they pretend that they would like to collaborate. Indeed, the last five years have even seen a marked deterioration in trust levels. 
With procurement IS, each firm can provide very specific know-how and make this available to other firms doing the same. The approach is the same as in a community of practices where everyone contributes to other members' wealth. At the same time, individuals are reluctant to share the things that create value for them without being guaranteed compensation that is at least equivalent. Power relationships are more accentuated in procurement IS than in traditional markets since perceptions of interactions are amplified by the virtual modes of communication that have replaced geographic proximity. Power wielded by some leads to domination over others who must then adopt a defensive posture and reject the tool that they sense their partners want to impose on them. The collective choice of a reliable IS reduces suspicion of partners who do not play by the rules and try to hide their failings by falsifying data. Securing information and ensuring its tracability is crucial in this respect.

\section{Conclusion}

People rely on procurement IS to construct, disseminate and pilot sustainable procurement policies and improve performance. Products and services that are labeled and have been guaranteed in codes of conduct can cost between 0 and $10 \%$ more. Purchasers are prepared to pay this to contribute to their company's good image, especially since such goods often offer better value for money than their more standard counterparts do. Green products remain harder to access, although depending on the sector in question, the relevant branches are becoming more identifiable. Among other tasks, purchasers must ensure that suppliers adhere to an industrial policy that is compatible with sustainability principles. For this, they increasingly rely on different sorts of procurement IS. The awareness is rising that collaboration comprises a major strategic issue enabling people to capitalize upon knowledge, ascertain joint projects and guarantee the financial viability of all commercial partners. Sustainable development has become a major organizational performance criterion, an indicator of the procurement function's maturity and a broadening of the concept of total quality. It involves the development of new digital collaborative platforms enabling practices that are more in line with the green mindset with which companies would like to associate their image.

\section{References}

1. Allal-Chérif, O.: An Economic Model for Electronic Marketplaces, Ph.D in Management Sciences (Mai 2007)

2. Allal-Chérif, O., Poissonnier, H., Maira, S.: Prospective du management de la fonction Achats: vers l'Acheteur Collaboratif. In: $10^{\text {eme }}$ colloque prospective des métiers: le Management de Demain, Mars 16, ESSEC, Paris, Mars 16 (2010)

3. Allemand, S.: Le développement durable: au regard de la prospective du présent. L'Harmattan, Paris (2006)

4. Barringer, B., Harrisson, J.S.: Walking a tightrope: creating value through interorganizational relationships. Journal of Management 26(3) (2000)

5. Berger, P.L., Luckmann, T.: The social construction of reality. A treatise in the sociology of knowledge, Doubleday, New York (1966) 
6. Dey, I.: Grounding Grounded Theory: Guidelines for Qualitative Inquiry. Kluwer, San Diego (1999)

7. Emiliani, M.L.: Business-to-business online auctions: key issues for procurement process improvement. Supply Chain Management 5(4) (2000)

8. Girin, J.: L'analyse empirique des situations de gestion. In: Martinet, A.C. (ed.), Épistémologies et Sciences de Gestion, Paris, Economica, pp. 141-182 (1990)

9. Granovetter, M.: Economic Action and Social Structure: the Concept of Embeddedness. American Journal of Sociology 91(3), 481-510 (1985)

10. Hamel, G., Prahalad, C.K.: The core competences of the corporation. In: Montgomery, C.A., Porter, M.E. (eds.) Strategy: seeking and securing a competitive advantage, pp. 277 299. Harvard Business School Press, Boston (1991)

11. Jarrosson, B.: Vers l'économie 2.0: du boulon au photon, Eyrolles (2009)

12. Miles, M.B., Huberman, A.M.: Analyse des données qualitatives, Éditions De Boeck (2003)

13. Miles, R.E., Snow, C.C.: Causes of Failure in Network Organizations. California Management Review 34(4), 53-72 (Summer 1992)

14. Quairel, F., Auberger, M.-N.: Management responsable et PME: Une relecture du concept de responsabilité sociétale de l'entreprise. La Revue des Sciences de Gestion, Direction et Gestion (211-212), 111-126 (2005)

15. Rogers, C.: The non directive method as a technic for social research. American Journal of Sociology 50(4), 279-283 (1945)

16. Veltz, P.: La mondialisation, villes et territoires, Puf, Paris (1996)

17. Wacheux, D.: Méthodes Qualitatives et Recherche en Gestion, Economica (1996) 